\title{
PROPAGAÇÃo DE GENÓTIPOS DE PITANGUEIRA (Eugenia uniflora L.) PELO MÉTODO DE ENXERTIA DE GARFAGEM NO TOPO EM FENDA CHEIA ${ }^{1}$
}

\author{
JOÃO EMMANOEL FERNANDES BEZERRA², ILDO ELIEZER LEDERMAN ${ }^{3}$, \\ ERINALDO VIANA DE FREITAS ${ }^{4} \&$ JOSUÉ FRANCISCO DA SILVA JÚNIOR ${ }^{5}$
}

\begin{abstract}
RESUMO - O trabalho foi conduzido na Estação Experimental de Itambé - IPA, em Itambé - PE, com o objetivo de avaliar o pegamento da enxertia pelo processo de garfagem no topo em fenda cheia, em porta-enxertos com nove meses de idade, de dez genótipos de pitangueira usados como copa. O delineamento experimental foi o de blocos ao acaso, com três repetições e dez tratamentos (IPA-1.1; IPA-1.3; IPA-2.2; IPA-3.1; IPA-3.2; IPA-4.3; IPA-7.3; IPA-11.3; IPA-14.3 e IPA-15.1). Os genótipos comportaram-se diferentemente quanto à capacidade de pegamento de enxertia, sendo IPA-7.3; IPA-2.2; IPA-11.3; IPA-4.3; IPA-3.1; IPA-14.3; IPA-15.1 e IPA-3.2 aqueles que apresentaram a melhor combinação enxerto x porta-enxerto, com valores de pegamento da enxertia variando de 81,5 a $53,5 \%$ para o primeiro e último genótipos, respectivamente. Os genótipos IPA-1.1 e IPA-1.3 obtiveram os menores percentuais de pegamento (20,0 e $38,5 \%$, respectivamente).
\end{abstract}

Temos para indexação: Propagação vegetativa, pitanga, Myrtaceae, enxerto.

\section{PROPAGATION OF SURINAM CHERRY (Eugenia uniflora L.) GENOTYPES BY CLEFT GRAFTING}

\begin{abstract}
In a trial carried out at Itambé Experimental Station - IPA, Pernambuco State, Brazil, ten Surinam cherry genotypes were cleft grafted on nine months old rootstocks in order to evaluate their grafting ability: IPA-1.1; IPA-1.3; IPA-2.2; IPA-3.1; IPA-3.2; IPA4.3; IPA-7.3; IPA-11.3; IPA- 14.3 and IPA-15.1. Genotypes behaved differently in its grafting ability, in which the majority of them has shown good relationship between rootstock $\mathrm{x}$ grafts. Grafting percentages ranged from $81.5 \%$ to $53.5 \%$ for the highest uptaking ( IPA7.3, IPA-2.2, IPA-11.3, IPA-4.3, IPA-3.1, IPA14.3, IPA-15.1 and IPA-3.2, respectively) and $20.0 \%$ to $38.5 \%$ for the lowest ones (IPA-1.1 and IPA-1.3, respectively).
\end{abstract}

Index terms: Vegetative propagation, Myrtaceae, graft, pitanga.

\section{INTRODUÇÃO}

O cultivo da pitangueira (Eugenia uniflora L.) no Estado de Pernambuco vem crescendo a cada ano em razão da utilização do seu fruto para o preparo de polpa e suco, bem como para a fabricação de sorvetes, refrescos, geléias, licores e vinhos (Lederman et al., 1992; Bezerra et al., 2000).

Apesar da expansão e do potencial econômico de exploração dessa cultura, a maioria dos pomares existentes é proveniente de plantas propagadas por sementes, o que tem refletido negativamente na condução dos pomares, resultando em plantas desuniformes, de baixa produtividade e dando origem a frutos de má qualidade.

A propagação vegetativa por meio da enxertia tem sido uma técnica bastante utilizada na fruticultura, garantindo a formação de pomares com populações de plantas homogêneas (Gonzaga Neto et al., 1982; Dantas et al., 1993; Lederman et al., 1997). Além disso, a enxertia possibilita a união de mais de um genótipo, combinando as características desejáveis de ambos em uma planta composta (Hartmann \& Kester, 1968).

Segundo Bezerra et al. (1999), os processos de enxertia dos tipos garfagem no topo em fenda cheia e à inglesa simples, realizados em porta- enxertos com 9 e 12 meses de idade, foram os métodos mais eficientes na propagação da pitangueira, alcançando-se com esses processos $77,5 \%$ de pegamento do enxerto.

Bezerra et al. $(1995,1997)$ relacionaram dez clones de pitangueira com elevado potencial produtivo e boas características agronômicas, para a região da Mata Pernambucana. No entanto, sabendo-se da existência de diferenças entre os clones estudados, as quais, segundo Simão (1971), podem afetar o pegamento de enxerto, em razão da influência recíproca entre o enxerto e o porta-enxerto, procurou-se, nesse trabalho, avaliar o melhor pegamento da enxertia entre os genótipos selecionados.

\section{MATERIALE MÉTODOS}

O trabalho foi conduzido no período de julho de 1999 a maio de 2000, na Estação Experimental de Itambé, da Empresa Pernambucana de Pesquisa Agropecuária - IPA, localizada no Município de Itambé, na Zona da Mata Norte de Pernambuco. O

1 (Trabalho 091/2001). Recebido: 24/04/2001. Aceito para publicação: 08/02/2002.

2 Eng. Agr., M.Sc., bolsista do CNPq, Empresa Pernambucana de Pesquisa Agropecuária - IPA, Caixa Postal 1022, CEP: 50761-000, Recife, PE. Email:emmanoel@ipa.br

3 Eng. Agr., Ph.D., Embrapa/IPA, bolsista CNPq; E-mail: ildo@ipa.br

4 Eng. Agr., B.Sc., IPA; E-mail: ipa@ipa.br

5 Eng. Agr., M.Sc., bolsista da Fundação de Amaparo à Ciência e Tecnologia de Pernambuco - Facepe, IPA; E-mail: josuef@ipa.br 
clima da região, de acordo com a classificação de Köppen, é do tipo As' - tropical chuvoso quente e úmido com verão seco.

Utilizou-se o delineamento experimental de blocos ao acaso, com três repetições, dez tratamentos e 20 plantas por parcela. Os tratamentos foram constituídos dos genótipos IPA1.1; IPA-1.3; IPA-2.2; IPA-3.1; IPA-3.2; IPA-4.3; IPA-7.3; IPA11.3; IPA-14.3 e IPA-15.1, utilizados como enxertos.

Para a formação dos porta-enxertos, utilizaram-se sacos de polietileno pretos, perfurados de $20 \times 35 \mathrm{~cm}$, contendo substrato de terra local e esterco de gado na proporção de 3:1. As mudas do porta-enxerto foram obtidas de sementes retiradas de frutos maduros colhidos de uma única planta.

O método de enxertia utilizado foi o de garfagem no topo em fenda cheia, realizado em porta-enxertos do genótipo IPA-2.2 com nove meses de idade e a $65 \mathrm{~cm}$ de altura, conforme procedimentos descritos por Bezerra et al. (1999). Os garfos com $10 \mathrm{~cm}$ de comprimento, $5 \mathrm{~mm}$ de diâmetro e aproximadamente cinco gemas foram coletados da porção mediana de ramos anuais lignificados.

As avaliações foram feitas aos 45 dias após a realização da enxertia, observando-se, para cada tratamento, o pegamento dos enxertos que apresentavam gemas vegetativas em crescimento. Para efeito da análise estatística dos resultados, os dados foram transformados em

\section{RESULTADOS E DISCUSSÃO}

As médias de pegamento de enxertos, em relação aos genótipos, estão apresentadas na Tabela 1. Comparando-se os percentuais de pegamento, verificou-se que oito genótipos se comportaram semelhantemente (IPA-7.3; IPA-2.2; IPA-11.3; IPA4.3; IPA-3.1; IPA-14.3; IPA-15.1 e IPA-3.2), apresentando percentuais acima de $53 \%$ de pegamento de enxerto. A maior porcentagem de pegamento de enxerto foi obtida pelo genótipo IPA-7.3 (81,5\%). Esses resultados coincidem com os citados por Bezerra et. al. (1999), que alcançaram percentuais da ordem de $77,5 \%$.

A menor percentagem de pegamento de enxerto foi para o genótipo IPA-1.1 (20,0\%), que diferiu de todos os outros genótipos estudados com exceção do IPA-1.3 (38,5\%). Acreditase que os baixos percentuais encontrados para esses genótipos estejam relacionados com a qualidade dos garfos utilizados, os quais poderiam não estar suficientemente maduros (lignificados) para permitir o pegamento. Ou ainda, ao fato de os porta-enxertos usados terem sido provenientes de sementes, o que produziria uma certa variabilidade genética nos mesmos.

Outra possibilidade pode ser atribuída a uma reduzida compatibilidade entre enxerto e porta-enxerto, já que ela é função da afinidade fisiológica e anatômica. Segundo Simão (1971), a primeira diz respeito à região da enxertia, que pode tornar-se seletiva, dificultando o transporte de elementos maiores, micronutrientes e compostos orgânicos da raiz para a copa e vice-versa. A outra consiste na íntima associação dos tecidos cambiais de maneira a formarem uma conexão contínua que pode ser comprometida quando a copa e o porta-enxerto possuem células diferentes quanto ao tamanho, forma e consistência.
TABELA 1 - Números e porcentagens de pegamento de enxertos aos 45 dias da enxertia em relação aos clones estudados. Itambé-PE, 2000.

\begin{tabular}{lcc}
\hline Tratamento & $\begin{array}{c}\text { Número de pegamentos } \\
\text { [Dados transformados em } \\
(\sqrt{\mathbf{x + 0 , 5}})]\end{array}$ & $\begin{array}{c}\text { Porcentagem de } \\
\text { pegamento } \\
\text { (Dados originais) }\end{array}$ \\
\hline IPA-7.3 & $4,1 \mathrm{a}$ & 81,5 \\
IPA-2.2 & $3,9 \mathrm{a} \mathrm{b}$ & 73,5 \\
IPA-11.3 & $3,9 \mathrm{a} \mathrm{b}$ & 73,5 \\
IPA-4.3 & $3,8 \mathrm{a} \mathrm{b}$ & 70,5 \\
IPA-3.1 & $3,7 \mathrm{a} \mathrm{b}$ & 66,5 \\
IPA-14.3 & $3,6 \mathrm{a} \mathrm{b}$ & 61,5 \\
IPA-15.1 & $3,5 \mathrm{a} \mathrm{b}$ & 61,5 \\
IPA-3.2 & $3,3 \mathrm{a} \mathrm{b}$ & 53,5 \\
IPA-1.3 & $2,8 \mathrm{~b} \mathrm{c}$ & 38,5 \\
IPA-1.1 & $2,1 \quad \mathrm{c}$ & 20,0 \\
\hline
\end{tabular}

Médias seguidas da mesma letra na coluna não diferem significativamente entre si, pelo teste de Tukey, a $5 \%$ de probabilidade.

\section{CONCLUSÕES}

1. Os genótipos de pitangueira comportam-se diferentemente quanto à capacidade de pegamento de enxertia.

2. Os genótipos que apresentaram melhor pegamento de enxertia foram IPA-7.3; IPA-2.2; IPA-11.3; IPA-4.3; IPA-3.1; IPA-14.3; IPA15.1 e IPA-3.2.

3. Os genótipos IPA-1.1 e IPA-1.3 obtiveram os menores percentuais de pegamento de enxertia.

\section{REFERÊNCIAS BIBLIOGRÁFICAS}

BEZERRA, J.E.F.; SILVA JÚNIOR, J.F. da; LEDERMAN, I.E. Pitanga (Eugenia uniflora L.). Jaboticabal, SP: FUNEP, 2000. 30 p. (Série Frutas Nativas, 1).

BEZERRA, J.E.F; LEDERMAN, I.E.; FREITAS, E.V. de; SANTOS, V.F. dos. Método de enxertia e idade de porta-enxerto na propagação da pitangueira (Eugenia uniflora L.). Revista Brasileira de Fruticultura, Jaboticabal, v. 21, n. 3, p. 262-265, 1999.

BEZERRA, J.E.F; FREITAS, E.V. de; LEDERMAN, I.E.; DANTAS, A.P. Performance of surinam cherry (Eugenia uniflora L.) in Pernambuco, Brazil. II - Productive period 1989-1995. Acta Horticulturae, Wageningen, n. 452, p. 137-142. 1997.

BEZERRA, J.E.F; LEDERMAN, I.E.; PEDROSA, A.C; DANTAS, A.P.; FREITAS, E.V. de. Performance of surinam cherry (Eugenia uniflora L.) in Pernambuco, Brazil. Acta Horticulturae, 
Wageningen, n. 370, p. 77-81. 1995.

DANTAS, A.P.; PEDROSA, A.C.; LEDERMAN, I.E.; BEZERRA, J.E.F.; MELO NETO, M.L. de. Técnicas de enxertia na propagação da pinheira (Annona squamosa L.) em viveiro. Revista Brasileira de Fruticultura, Cruz das Almas, v. 15, n. 1, p. 235-238, 1993.

GONZAGANETO,L.; ANDERSEN,O.; PINHEIRO, R.V.R.; SILVA, F.C.C. da; CONDE, A.R. Estudos de métodos de produção de porta-enxerto e enxertia da goiabeira. III - Análises de crescimento em porta-enxertos. Revista Brasileira de Fruticultura, Cruz da Almas, v. 4, n. único, p. 59-66, 1982.

HARTMANN, H.T.; KESTER, D.E. Plant propagation principles and practices. 2. ed. Englewood Cliffs, New Jersey: PrenticeHall, 1968. 702 p.

LEDERMAN, I.E.; BEZERRA, J.E.F; CALADO, G. A pitangueira em Pernambuco. Recife, PE: IPA, 1992.20 p. (IPA. Documentos, 19).

LEDERMAN, I.E.; SILVA, M.F.F. da; BEZERRA, J.E.F; SANTOS, V.F. dos. Influência da idade do porta-enxerto e do tipo de enxertia na propagação da gravioleira. Pesquisa Agropecuária Brasileira, Brasília, v. 32, n. 6, p. 613-615, 1997.

SIMÃO, S. Manual de fruticultura. São Paulo: Ceres, 1971. 530 p. 